\title{
Determination of Morin and Quercetin in Fruit Juice Samples using Air-Assisted Liquid-Liquid Microextraction Based on Solidification of Floating Organic Droplet and HPLC-UV
}

\author{
Armin Fallah and Mohammad Reza Hadjmohammadi* \\ Department of Analytical Chemistry, Faculty of Chemistry, University of Mazandaran, NirooHavayii boulevard, \\ 47416-95447 Babolsar, Iran \\ * Corresponding author: E-mail: hadjmr@umz.ac.ir \\ Tel.: +98 1135342350; fax: +98 1135342350
}

Received: 02-05-2020

\begin{abstract}
In this study, a rapid and efficient method has been used for the extraction and determination of morin and quercetin in fruit juice samples based on air-assisted liquid-liquid microextraction based on solidification of floating organic droplet and HPLC-UV. The effects of 7 important parameters on the extraction recovery were examined and were optimized by Plackett-Burman design and Central Composite design. According to the Plackett-Burman design results, ionic strength of the sample solutions, the aspiration/dispersion cycles, and the rate and time of centrifuge did not show significant effects on the extraction of morin and quercetin. The optimized conditions of extraction were as follows; the volume of the extraction solvent of $83.6 \mu \mathrm{L}, \mathrm{pH}$ of 4.34 for the sample, and 1-undecanol as extraction solvent. Under these conditions, the linear calibration curve was in the ranges of $1-1000 \mathrm{ng} / \mathrm{mL}$ and $0.5-1000 \mathrm{ng} / \mathrm{mL}$ for morin and quercetin, respectively, with the determination coefficient values above 0.99 . The limit of detection of morin and quercetin was 0.3 and 0.2 $\mathrm{ng} / \mathrm{mL}$, respectively. The extraction recoveries for $10 \mathrm{ng} / \mathrm{mL}$ of morin and quercetin were $98.9 \%$ and $96.5 \%$, respectively; while, relative standard deviations $(n=3)$ were lower than $3.2 \%$.
\end{abstract}

Keywords: Morin; quercetin; fruit juices, air-assisted liquid-liquid microextraction based on solidification of floating organic droplet; HPLC

\section{Introduction}

Flavonoids are an important group of natural polyphenolic compounds, which are the essential plant metabolites with antioxidant activity. ${ }^{1}$ Morin (MR) and quercetin (QR) are isomeric antioxidant flavonols widely distributed in fruits and vegetables. ${ }^{2}$ Studies have shown that MR has numerous pharmacological activities such as coronary artery disease prevention, inhibition of proliferation of tumors, antioxidant, anticancer, anti-inflammatory, as well as free radicals scavenging activity. ${ }^{3}$ It has been published that QR has several biological properties in the inhibition of human diseases, such as cancer, ulcer, diabetes, cataract, and allergies. ${ }^{4}$

Based on these activities, many investigations have been undertaken to determine QR and MR in recent decades. Several techniques including high-performance liq- uid chromatography (HPLC), ${ }^{5-7}$ thin-layer chromatography (TLC), ${ }^{8}$ gas chromatography (GC), ${ }^{9}$ micellar electrokinetic chromatography (MEKC), ${ }^{10}$ capillary electrophoresis $(\mathrm{CE}),{ }^{11}$ and electrochemical methods ${ }^{12}$ have been employed for the determination of MR and/or QR in various samples.

Due to the low concentration of the target compounds in the samples and the complexity of the real sample, the sample preparation step plays a crucial role in the analysis of QR and MR. Thus, the extraction methods including solid-phase extraction (SPE), ${ }^{13-14}$ dispersive micro-solid-phase extraction, ${ }^{15}$ liquid-liquid extraction (LLE), ${ }^{16}$ molecularly imprinted polymer (MIP) ${ }^{17}$ and inverted dispersive liquid-liquid microextraction (IDLLME) ${ }^{18}$ have been utilized for the preconcentration of $\mathrm{MR}$ or/and QR.

Conventional sample preparation techniques for the preconcentration of flavonoids are based on SPE and 
LLE. ${ }^{16}$ These techniques are inadequate for the analysis of the fruit juice samples due to the high consumption of dangerous and expensive organic solvents and time-consuming processes. Thus, various microextraction techniques were masterminded to overcome SPE and LLE disadvantages.

In 2006, Rezaee et al. developed a method based on the LPME method called dispersive liquid-liquid microextraction (DLLME). It was widely used because of its advantages like simplicity, high enrichment factor, and low costs. In DLLME, a three-phase solvent system including the extraction solvent, the aqueous solution sample, and the organic disperser solvent is used. ${ }^{19}$ Despite the previously mentioned advantages, DLLME is not considered a biocompatible method because it uses a disperser solvent and toxic organic extractants such as dichloromethane, carbon tetrachloride, and chloroform. The DLLME-SFO method was introduced in $2007 .{ }^{20}$ In this method, solvents with the melting points near the room temperature and less toxicity were used. However, using the organic disperser solvent in this method can increase the consumption of the dangerous solvent. To solve this problem, these methods were replaced by methods such as VALLME ${ }^{21}$ and USAEME $^{22}$ that do not have the disperser solvent. These methods use vortex or ultrasonic waves to help the distribution of the organic phase in the aqueous solution. The AALLME method is another transformation that has been done on the DLLME method.

In 2012, AALLME method was introduced by Farajzadeh et al. to improve the performance of the extraction techniques. ${ }^{23}$ This method does not use the disperser solvent. After the injection of the extraction solvent, the mixture is sucked into one glass syringe and then injected in the sample tube repeatedly. Equilibrium is achieved quickly due to this process and the analyte to carry from the aqueous phase to the organic phase which is one of its main advantages. In this method, the production of a high number of tiny droplets of organic solvent in water leads to the increase in mass transfer; as a result, the extraction efficiency increases. Comparing AALLME with other DLLME methods indicates that this is more easy, efficient, and simple. ${ }^{24}$ This method has been recently used for the preconcentration of aromatic amines in the aqueous sample, ${ }^{25}$ tricyclic antidepressant drugs, ${ }^{26}$ azathioprine, ${ }^{27}$ bisphenols, parabens, benzophenones, triclosan, and triclocarban in human urine, ${ }^{28}$ benzophenone, ${ }^{29}$ and toxic heavy metals in food sample. ${ }^{30}$

The purpose of our study was to investigate the applicability of AALLME-SFO technique as a simple and fast method for the extraction of MR and QR from fruit juice samples and their analyses by RP-HPLC-UV. The disperser solvent was not used in this method. Also, the harmful effects of the toxic organic solvents on the operator and environment are decreased by replacing the heavy-density chlorine solvents with lighter and less toxic solvents. In addition, using the aeration method to increase the dispersion of the extraction solvent in the aqueous sample reduced the cost and the probability of the sample destruction. Also, it makes the process simpler compared to the ultrasonic or vortex. The fast injection of air into the sample solution has decreased the equilibration time. The main advantages of the proposed method are the simultaneous extraction of flavonoids in a short time along with high recovery, low detection limit, and low-cost. According to our knowledge, no usage of AALLME-SFO in the extraction of MR and QR from fruit juice samples has yet been reported. The effective factors were optimized in two stages by $\mathrm{PBD}$ and response surface methodology using the CCD. Also, this method was applied to several real samples.

\section{Experimental}

\section{1. Chemicals and Materials}

Quercetin ( $\geq 98 \%$ ), 1-dodecanol and 2-dodecanol were obtained from Sigma-Aldrich (Steinheim, Germany). Standard of morin ( $\geq 98 \%$ ), methanol (HPLC-grade), 1-undecanol, $n$-hexadecane, phosphoric acid, tetrahydrofuran (THF), and sodium chloride (98\%) were purchased from Merck (Darmstadt, Germany). DDW was utilized for the preparation of the mobile phase, which was filtered through a $0.45 \mathrm{~m}$ filter (Millipore membranes, Bedford MA, USA). The stock solution $(100 \mathrm{mg} / \mathrm{L})$ was prepared in methanol and stored at $4{ }^{\circ} \mathrm{C}$. The working solutions were prepared daily by diluting the standard solution with DDW.

\section{2. Instrumentation and Conditions}

Separation and detection were carried out by a Waters HPLC system equipped with a 1525 pump and a model 2487 UV detector set at $275 \mathrm{~nm}$ (Milford, MA, USA), $7725 \mathrm{i}$ manual injector (Cotati, CA, USA) fitted with a 20 $\mu \mathrm{L}$ loop. The isocratic elution was done at a flow rate of $1.0 \mathrm{~mL} / \mathrm{min}$ on a C18 $(250 \mathrm{~mm} \times 4.6 \mathrm{~mm}, 10 \mu \mathrm{m})$ column from Dr. Maisch GmbH (Beim Brueckle, Germany). The mobile phase consisted of methanol, $0.4 \%$ phosphoric acid, and THF (40:59.7:0.3, $v / v / v)$. For the adjustment of sample solution $\mathrm{pH}$, a 3030 Jenway $\mathrm{pH}$ meter was used. A Hettich centrifuge model Universal 320 (Kirchlengern, Germany) was utilized to accelerate the phase separation.

\section{3. Extraction Procedure}

Initially, $9 \mathrm{~mL}$ of the aqueous solution sample (containing $0.5 \mathrm{mg} / \mathrm{L}$ of each analyte) was added to a centrifuge tube. Then $100 \mu \mathrm{L}$ of 1-undecanol was injected into the aqueous sample by applying a syringe. The process of sucking out the mixture and rapidly injecting it was done several times. A cloudy solution was formed, and the compounds were extracted. The cloudy solution was then centrifuged at $5000 \mathrm{rpm}$ for $5 \mathrm{~min}$ to separate the phases. Then the sample vial was placed in a beaker containing ice for $5 \mathrm{~min}$ and 1 -undecanol was solidified accordingly. The 
solid solvent was transferred into a conical vial by spatula, where it rapidly melted. ${ }^{31}$ Finally, $20 \mu \mathrm{L}$ of the sample was injected into the HPLC-UV system.

\section{4. Real Samples Preparation}

Fresh apple, orange, red grape, peach, and commercial apple juice were purchased at a local supermarket. Apple, orange, red grape, and peach samples were placed in a commercial juice extractor. The resulted fruit juice samples and commercial apple juice were centrifuged for 15 $\mathrm{min}$ at $5000 \mathrm{rpm}$, and the supernatants were filtered. Finally, the $\mathrm{pH}$ of samples was adjusted to 4.3 using $\mathrm{HCl} 1$ $\mathrm{mmol} / \mathrm{L}$ and the extraction process was undertaken according to section 2.3 .

\subsection{Optimization Strategy}

In order to obtain the most desirable extraction conditions, various experimental parameters were investigated which according to past studies can potentially affect the extraction performance, such as type and volume of the extraction solvent, $\mathrm{pH}$ of the solution, amount of salt, number of extractions, and rate and time of the centrifuging process. These parameters were evaluated to select and determine the significant parameters to obtain the highest total peak areas. In the first step, PBD was used for screening the parameters and selecting the effective experimental factors. Then, RSM based on CCD was applied to determine the optimized point. The statistical analysis and experimental design were done by Minitab software. Also, it is essential to say that all the experiments were done three times.

\section{Results and Discussion}

The extraction recovery (ER) was applied to evaluate the extraction performance. The ER is calculated via the following equation:

$$
E R \%=\left(\frac{V_{o}}{V_{a q}}\right) E F \times 100
$$

Where $V_{\text {aq }}$ and $V_{\mathrm{o}}$ are the volumes of the aqueous and organic phases, respectively. EF is calculated according to the ratio of the final concentrations of analyte in the floating phase $\left(C_{\mathrm{o}}\right)$ to its initial concentration in an aqueous sample $\left(C_{\mathrm{aq}}\right)$.

$$
E F=\frac{c_{o}}{C_{a q}}
$$

\section{1. Selection of Extraction Solvent}

The selection of an appropriate extraction solvent is crucial in the optimization of the AALLME-SFO process because of the effects of its physical and chemical properties. In this study, the extraction solvent must have special features, such as lower density than water, low water solubility in order to be stable at the extraction period and to extract analytes well. Therefore, several extraction solvents, including 1 -dodecanol, $n$-hexadecane, 1 -undecanol, and 2-dodecanol were investigated. According to the results for three repeats, which are shown in Fig. 1, 1-undecanol showed the highest peak area for MR and QR compared to other solvents. This may be because of the good dispersion of this solvent in the aqueous sample and/or its hydrophobicity similar to the analytes. Hence, 1-undecanol was chosen as the extraction solvent for subsequent experiments.

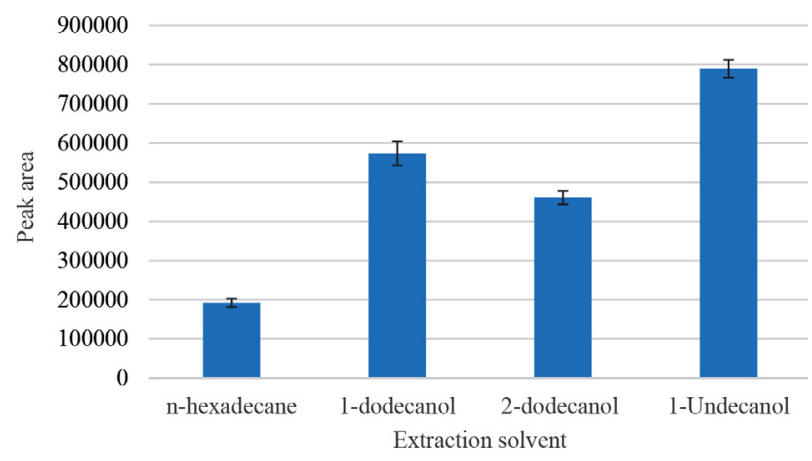

Figure 1. Selection of the extraction solvent used in the microextraction of morin and quercetin $(n=3)$.

\section{2. Screening of Significant Variables}

The PBD was used to screen the effective factors among the previously mentioned six experimental factors. PBD is based on the first-order polynomial model and does not define the exact value. It is an advantageous method for the quick search of the effective variables and calculation of their main effects in fewer experiments. ${ }^{32}$ Each of these factors was investigated at two levels. The experimental design included 12 experiments that were done. The sum of the peak areas was applied as the corresponding response to investigate the extraction in various conditions. The levels of factors were chosen according to the previous trials and 12 experiments were randomly done to avoid the uncontrollable errors. The main effects were determined by the analysis of variance (ANOVA) and the effective factors on the extraction were identified by the Pareto chart with the confidence level of 95\% (Fig. 2). The bars beyond the line are related to the significant effects. Based on these results, $\mathrm{pH}$ was identified as the most effective factor with a negative effect. The volume of the extraction solvent was considered as the second most effective factor after $\mathrm{pH}$. Therefore, these two factors were chosen for CCD in the next step. The level of the other factors was selected according to the previous experiment. Thus, in the following experiments, the number of ex- 


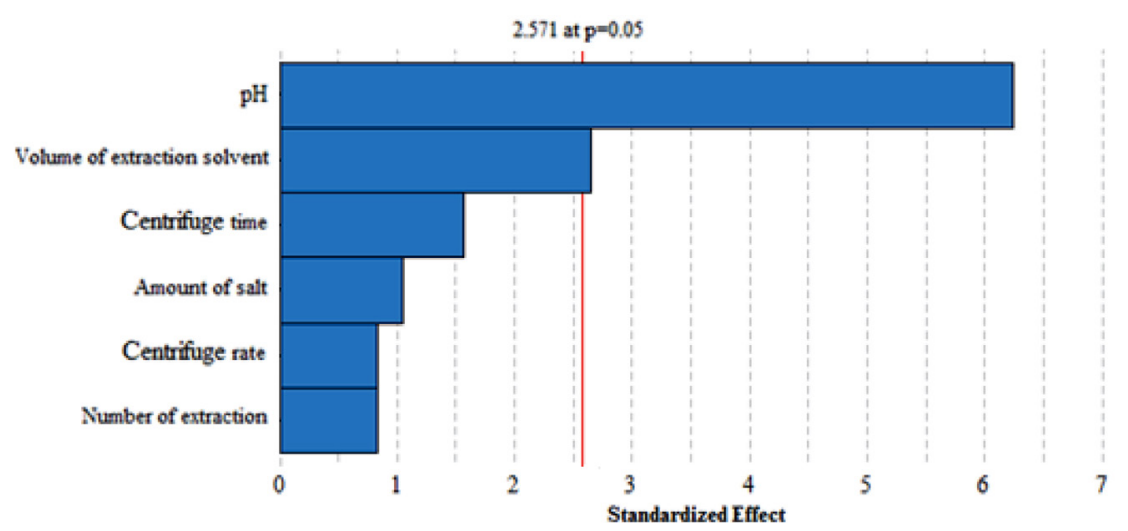

Figure 2. Pareto chart of the main effects obtained from the Plackett-Burman design.

tractions, the amount of salt, the rate and time of centrifuge were set at 15 cycles, $0 \mathrm{mg} / \mathrm{mL}, 5000 \mathrm{rpm}$, and $8 \mathrm{~min}$, respectively.

\section{3. Optimization of Extraction Conditions}

To achieve the proper response surface for the extraction of MR and QR with the AALLME-SFO method, CCD was used. To determine the optimal point in this method, it is necessary to examine the effect of each factor on the five levels coded as $\alpha,-\alpha$ (axial points), 1,-1 (factorial points), and 0 (central point). The significant factors and their levels are shown in Table S1. The following equation calculates the number of experiments $(\mathrm{N})$ in CCD:

$$
N=2^{K}+2 K+C p
$$

In this equation, $\mathrm{K}$ and $\mathrm{Cp}$ are the number of the factors and repetitions of the experiments in the central point, respectively. Table S2 shows the design matrix. Also, the trials were carried out randomly to decrease the effects of uncontrolled variables. The results of the CCD method were evaluated by ANOVA at $95 \%$ confidence level (Table 1 ). The $p$-value for the LOF of the model was 0.291 , thus, LOF was not significantly related to the pure error. Thus, the best second-order equation that matched the data was achieved as follows:

$$
\begin{aligned}
\text { Peak area }= & 832762-65731 X_{1}-19826 X_{2}- \\
& -80181 X_{1}^{2}-44538 X_{1} \\
& * X_{2}
\end{aligned}
$$

The coefficient of determination $\left(\mathrm{R}^{2}\right)$ value for this model was $92.6 \%$, which showed that this model could explain $92.6 \%$ of the variability of the responses. The response surface of the experiments according to the above model is shown in Fig. 3. The response surfaces showed that by increasing the amount of $\mathrm{pH}$, the response increases accordingly. Also, by increasing the volume of 1-undecanol, the response will fluctuate (first increases and then decreases).

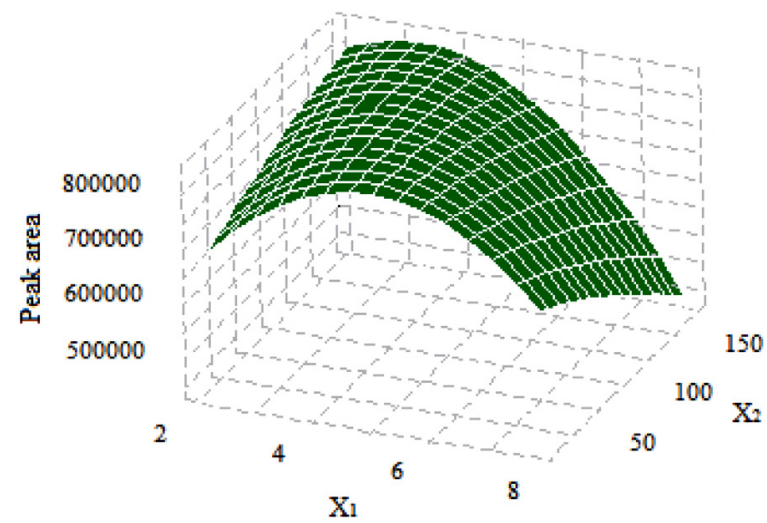

Figure 3. The response surface plots for the peak area as a function of the $\mathrm{pH}$ of the sample solution and volume of extraction solvent.

Table 1. Analysis of Variance (ANOVA) of CCD

\begin{tabular}{crrrrr}
\hline Source & DF & \multicolumn{1}{c}{ Adj SS } & \multicolumn{1}{c}{ Adj MS } & F-Value & P-Value \\
\hline $\mathrm{X}_{1}$ & 1 & 34564032309 & 34564032309 & 168.38 & 0.000 \\
$\mathrm{X}_{2}$ & 1 & 3144553668 & 3144553668 & 15.32 & 0.006 \\
$\mathrm{X}_{1}{ }^{2}$ & 1 & 44331878523 & 44331878523 & 217.87 & 0.000 \\
$\mathrm{X}_{2}{ }^{2}$ & 1 & 437028613 & 437028613 & 2.13 & 0.188 \\
$\mathrm{X}_{1} \mathrm{X}_{2}$ & 1 & 7934444700 & 7934444700 & 38.65 & 0.000 \\
Residual Error & 7 & 1436943011 & 205277573 & & \\
Lack-of-Fit & 3 & 819802309 & 273267436 & 1.77 & 0.291 \\
Pure Error & 4 & 617140703 & 154285176 & & \\
Total & 12 & 91848880824 & & & \\
\hline
\end{tabular}


Therefore, the optimal values for $\mathrm{pH}$ and the volume of 1-undecanol were obtained as 4.34 and $83.6 \mu \mathrm{L}$, respectively. To evaluate the predicted optimum conditions, the experiment was replicated three times and the average of ERs was satisfactorily consistent with the predicted results.

\section{4. Method Validation}

The analytical performance of this method including RSD, LOD, LOQ, the recovery of extraction (ER), the linear range (LR), and the enrichment factor (EF) was studied by plotting the calibration curves for the MR and QR samples, and the further calculations were done about them. The linear range was investigated for each sample solution, and it was in the range of 1-1000 ng/mL for MR and 0.5-1000 ng/ $\mathrm{mL}$ for $\mathrm{QR}$ with $\mathrm{R}^{2}>0.99$ for both compounds, respectively. The LODs of MR and QR at the signal-to-noise ratio of 3 (S/ $\mathrm{N}=3$ ) were calculated as 0.3 and $0.2 \mathrm{ng} / \mathrm{mL}$, respectively. The LOQ was calculated based on the signal-to-noise ratio of $10(\mathrm{~S} / \mathrm{N}=10)$. The RSDs $(\mathrm{n}=3)$ were calculated as lower than $3.2 \%$ for $10 \mathrm{ng} / \mathrm{mL}$ of $\mathrm{MR}$ and $\mathrm{QR}$. Their values are suitable and confirm the application of this technique. The analytical performance results are shown in Table 2.

\section{5. Analysis of the Real Samples}

To investigate the applicability of the proposed method for determining flavonoids in real samples, apple,

Table 2. Analytical performance of AALLME-SFO for the determination of morin and quercetin

\begin{tabular}{|c|c|c|c|c|c|c|c|c|}
\hline \multirow{2}{*}{ Sample } & \multirow[b]{2}{*}{ LOD $(\mathrm{ng} / \mathrm{mL})$} & \multirow[b]{2}{*}{ LOQ $(\mathrm{ng} / \mathrm{mL})$} & \multirow[b]{2}{*}{ LR (ng/mL) } & \multirow[b]{2}{*}{$\mathbf{R}^{2}$} & \multicolumn{2}{|c|}{ RSD (\%) } & \multirow[b]{2}{*}{ EF } & \multirow[b]{2}{*}{ ER\% } \\
\hline & & & & & Intra-day $(n=3)$ & Intra-day $(n=3)$ & & \\
\hline morin & 0.3 & 0.9 & $1-1000$ & 0.996 & 2.6 & 3.2 & 106.5 & 98.9 \\
\hline quercetin & 0.2 & 0.6 & $0.5-1000$ & 0.999 & 1.7 & 2.2 & 104 & 96.6 \\
\hline
\end{tabular}

Table 3. The application of presented method for the determination of morin and querectin in fruit juices samples

\begin{tabular}{|c|c|c|c|c|c|}
\hline Sample & Analyte & $C_{\text {added }}(\mathbf{n g} / \mathbf{m L})$ & $C_{\text {found }}(\mathbf{n g} / \mathbf{m L})$ & $\operatorname{RSD} \%(\mathbf{n}=3)$ & RR \% \\
\hline \multirow{6}{*}{ Apple juice } & morin & - & 7.3 & - & - \\
\hline & & 10 & 17.1 & 2.4 & 97.5 \\
\hline & & 30 & 36.0 & 3.0 & 95.7 \\
\hline & querectin & - & 9.7 & - & - \\
\hline & & 10 & 18.6 & 2.8 & 89 \\
\hline & & 30 & 37.5 & 2.1 & 92.7 \\
\hline \multirow{6}{*}{ Red grape juice } & morin & - & 6.7 & - & - \\
\hline & & 10 & 16.3 & 3.1 & 96.2 \\
\hline & & 30 & 34.7 & 2.7 & 93.3 \\
\hline & querectin & - & 12.7 & - & - \\
\hline & & 10 & 22.5 & 3.3 & 98 \\
\hline & & 30 & 41.8 & 2.9 & 97 \\
\hline \multirow{6}{*}{ Commercial apple juice } & morin & - & N.D & - & - \\
\hline & & 10 & 9.9 & 3.6 & 99.5 \\
\hline & & 30 & 27.3 & 3.4 & 91 \\
\hline & querectin & - & N.D & - & - \\
\hline & & 10 & 8.8 & 3.1 & 87.8 \\
\hline & & 30 & 27.6 & 3.7 & 92.1 \\
\hline \multirow{6}{*}{ Orange juice } & morin & - & 14.5 & - & - \\
\hline & & 10 & 24.0 & 3.5 & 95 \\
\hline & & 30 & 42.8 & 3.4 & 94.2 \\
\hline & querectin & - & 8.6 & - & - \\
\hline & & 10 & 18.3 & 3.7 & 96.8 \\
\hline & & 30 & 38.3 & 2.8 & 99 \\
\hline \multirow{6}{*}{ Peach juice } & morin & - & N.D & - & - \\
\hline & & 10 & 9.6 & 2.6 & 96.4 \\
\hline & & 30 & 28.7 & 3.2 & 95.7 \\
\hline & querectin & - & 1.8 & - & - \\
\hline & & 10 & 12.0 & 3.6 & 102 \\
\hline & & 30 & 29.8 & 3.3 & 93.2 \\
\hline
\end{tabular}


commercial apple, red grape, peach, orange, and commercial apple juice samples were studied under the optimized conditions. The determination of morin and quercetin was carried out by the standard addition method. The samples were spiked with standards at three levels, extracted, and eventually analyzed by HPLC (Table. 3 ). The relative recovery (RR) of MR and QR was calculated as follows:

$$
R R=\frac{C_{\text {found }}-C_{\text {real }}}{C_{\text {added }}} \times 100
$$
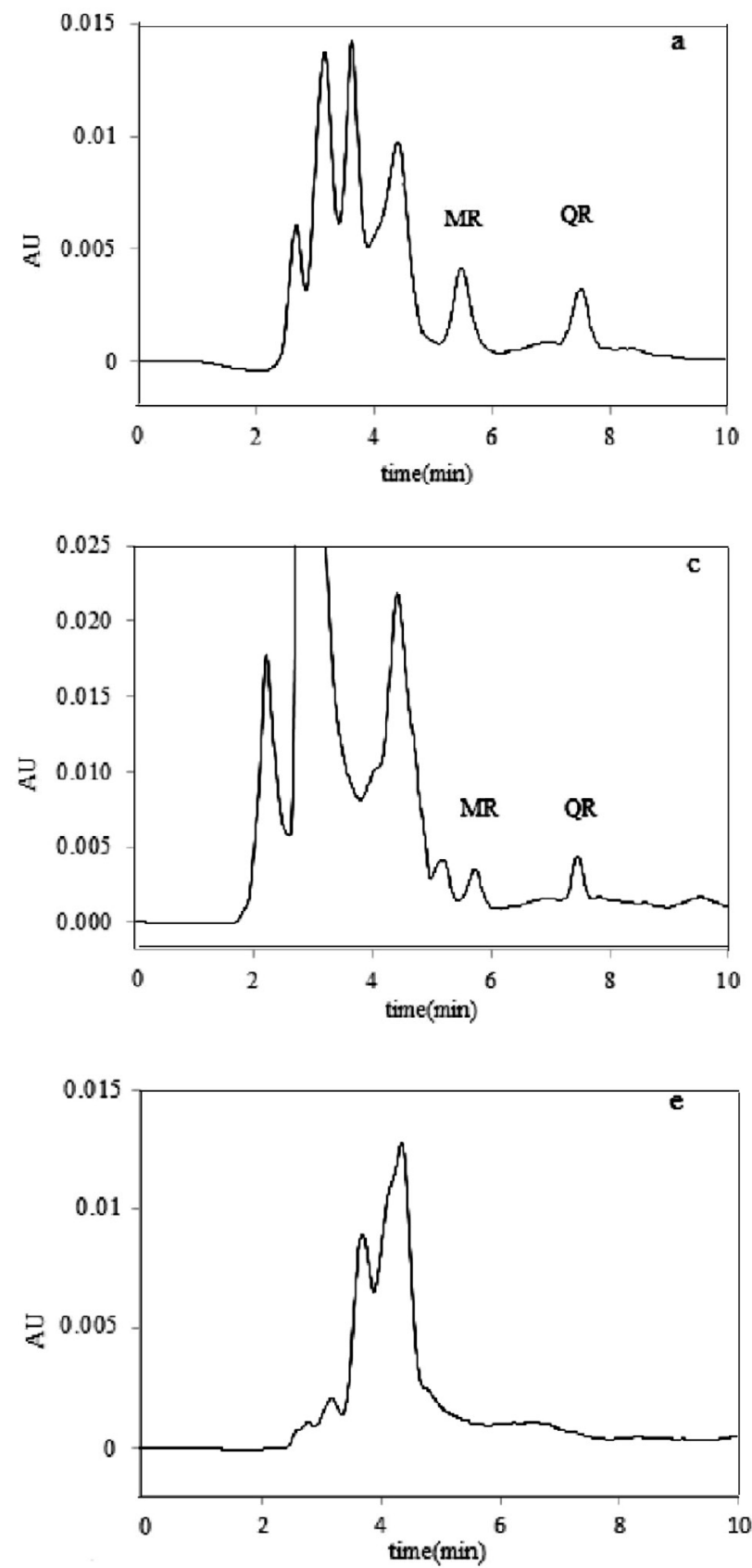

where $C_{\text {found }}$ and $C_{\text {real }}$ are the concentration of analyte after adding a known amount of the standard to the real sample, and the initial concentration of the analyte in the real sample, respectively. $C_{\text {added }}$ also represents the spiked standard concentration in the real sample. The analytical results are shown in Table 3. Regarding the complexity of the matrices studied, the extraction recoveries for MR and QR were compatible with those values of the standard that was added to the samples; while, the RSDs $(n=3)$ were lower than $3.7 \%$. Fig. 4 shows the obtained chromatograms for each sample.
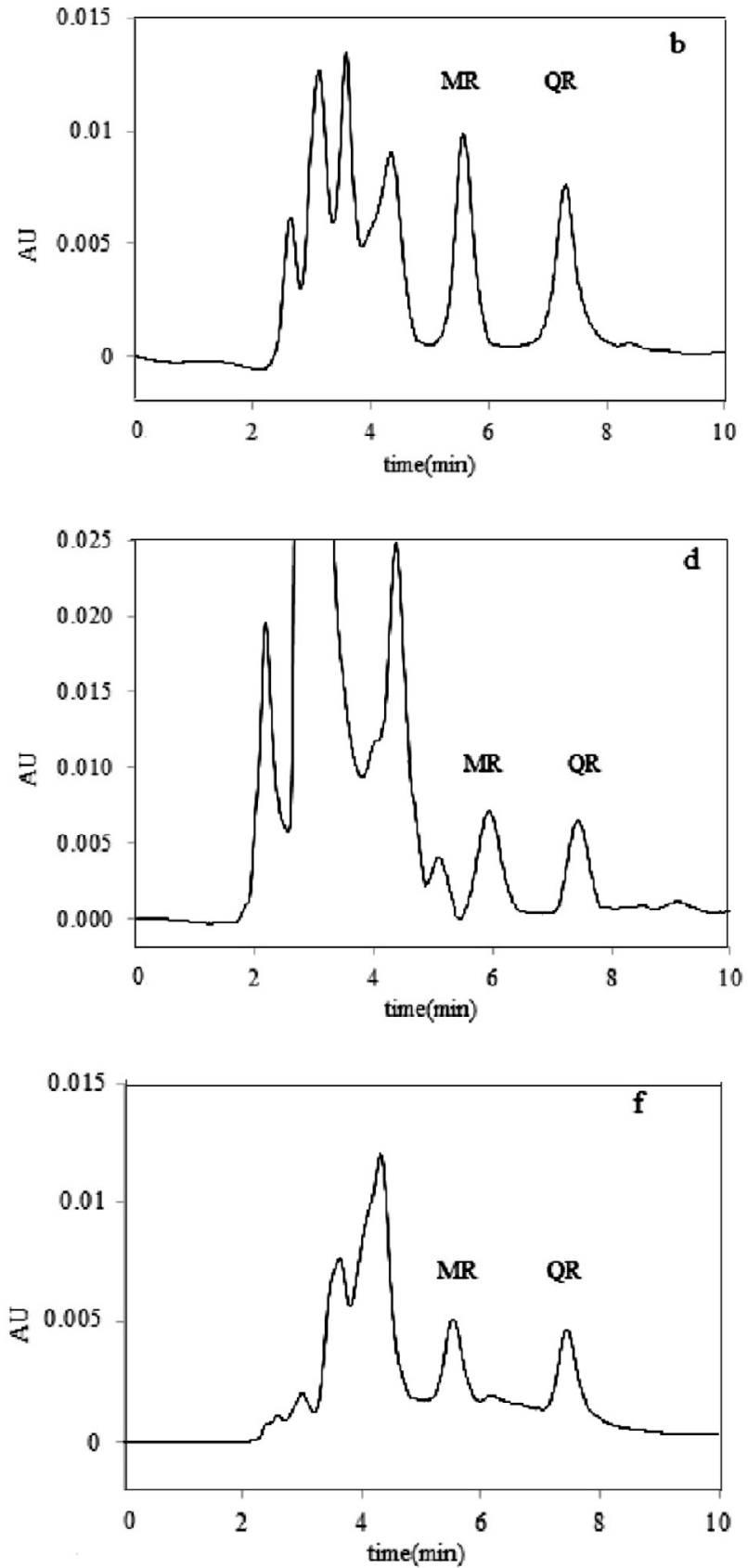

Figure 4. Typical chromatograms of (a) orange sample; (b) spiked orange sample; (c) apple sample; (d) spiked apple sample; (e) commercial apple sample; (f) spiked commercial apple sample. HPLC conditions and experimental details were described in the text. Samples were spiked with $10 \mathrm{ng} /$ $\mathrm{mL}$ of $\mathrm{MR}$ and $\mathrm{QR} . \mathrm{MR}=$ morin and $\mathrm{QR}=$ quercetin. 
Table 4. Comparison between the presented method and other reported methods for the determination of morin and quercetin

\begin{tabular}{|c|c|c|c|c|c|c|c|c|}
\hline Method & Sample & Analyte & LOD & LR & RSD\% & RE\% & Time of extraction & Ref. \\
\hline $\begin{array}{c}\text { Dispersive } \\
\text { micro-SPE-HPLC }\end{array}$ & $\begin{array}{l}\text { Onion, apple } \\
\text { and green tea }\end{array}$ & morin & 0.91 & $3-500$ & 3.8 & 97.7 & medium & {$[15]$} \\
\hline HF-LPME-HPLC & $\begin{array}{l}\text { E. platylob DC. } \\
\text { and M. piperita }\end{array}$ & $\begin{array}{l}\text { morin } \\
\text { quercetin }\end{array}$ & $\begin{array}{c}1.5 \\
4\end{array}$ & $\begin{array}{c}5-500 \\
10-500\end{array}$ & $\begin{array}{l}3.2 \\
4.6\end{array}$ & $\begin{array}{l}80 \\
45\end{array}$ & medium & {$[33]$} \\
\hline DSDME-GC-MS & $\begin{array}{c}\text { Fruit juices } \\
\text { and functional foods }\end{array}$ & quercetin & $\begin{array}{c}0.06 \\
1\end{array}$ & $0.5-500$ & 6 & 99 & high & {$[34]$} \\
\hline IDLLME-HPLC-UV & $\begin{array}{l}\text { Plasma, urine } \\
\text { and honey }\end{array}$ & quercetin & 0.26 & $0.5-500$ & $<5$ & 97 & low & {$[18]$} \\
\hline$U A-D-\mu-S P E-U V-V i s$ & $\begin{array}{l}\text { Nasturtium officinale } \\
\text { extract and fruit juice }\end{array}$ & quercetin & 4.35 & $20-4000$ & $<6$ & $90.3-97.28$ & medium & {$[35]$} \\
\hline SBME-DES-HPLC-UV & $\begin{array}{l}\text { Apple, orange, } \\
\text { pineapple, onion }\end{array}$ & $\begin{array}{l}\text { morin } \\
\text { quercetin }\end{array}$ & $\begin{array}{l}0.2 \\
2.6\end{array}$ & $\begin{array}{c}1-500 \\
10-500\end{array}$ & $\begin{array}{l}2.3 \\
3.6\end{array}$ & $\begin{array}{l}90.3 \\
94.4\end{array}$ & medium & {$[36]$} \\
\hline SPE-HPLC-UV & $\begin{array}{l}\text { plasma } \\
\text { urine }\end{array}$ & $\begin{array}{l}\text { quercetin } \\
\text { quercetin }\end{array}$ & $\begin{array}{l}0.35 \\
0.35\end{array}$ & $\begin{array}{c}4-700 \\
20-1000\end{array}$ & $\begin{array}{c}7 \\
35\end{array}$ & - & high & {$[37]$} \\
\hline $\begin{array}{l}\text { AALLME-SFO- } \\
\text { HPLC-UV }\end{array}$ & Fruit juices & $\begin{array}{c}\text { morin } \\
\text { quercetin }\end{array}$ & $\begin{array}{l}0.28 \\
0.19\end{array}$ & $\begin{array}{c}1-1000 \\
0.5-1000\end{array}$ & $\begin{array}{l}3.2 \\
2.2\end{array}$ & $\begin{array}{l}98.9 \\
96.6\end{array}$ & low & $\begin{array}{c}\text { Present } \\
\text { study } \\
\text { Present } \\
\text { study }\end{array}$ \\
\hline
\end{tabular}

According to Table 4, a comparison between the AALLME-SFO-HPLC-UV method and the other reported techniques for the extraction and determination of MR and $Q R$ indicates that the present method reveals low LOD, desirable linear range, and high extraction recovery. Furthermore, AALLME-SFO is a simple, inexpensive, and fast method for the preconcentration and extraction of $Q R$ and MR from fruit juice samples.

\section{6. Conclusion}

Affecting parameters on AALLME-SFO-HPLC-UV were optimized through CCD and the results showed that this method is applicable for the extraction, preconcentration, and determination of morin and quercetin in fruit juice samples. This technique is less harmful and, therefore, is more environmentally friendly than the conventional DLLME methods due to the use of low-density extraction solvent and non-consumption of the organic disperser solvent. Moreover, the possibility of a fast injection of air into the sample solution increases the surface contact between the extraction solvent and analytes. Fast equilibration of the extraction is another advantage of this method. The experimental results showed high recoveries, low detection limits, wide linearity range, simplicity of the extraction, and inexpensive and rapid extraction which make it useful to determine morin and quercetin in fruit juice samples.

\section{Abbreviations:}

AALLME-SFO, air-assisted liquid-liquid microextraction based on solidification of floating organic droplet;
ANOVA, analysis of variance; CCD, Central Composite design; DDW, double distilled/deionized water; DLLME-SFO, dispersive liquid-liquid microextraction based on solidification of floating organic droplet; EF, enrichment factor; $\mathrm{ER}$, extraction recovery; IDLLME, inverted dispersive liquid-liquid microextraction; LOD, limit of detection; LOF, lack of fit; LOQ, limit of quantification; LR, linear range; LLE, liquid-liquid extraction; LPME, liquid-phase microextraction; MIP, molecularly imprinted polymer; PBD, Plackett-Burman design; RE, recovery of extraction; RPM, rounds per minute; $R R$, relative recovery; $R S D$, relative standard deviation; RSM, response surface methodology; SPE, solid-phase extraction; TBP, tributyl phosphate; THF, tetrahydrofuran; USAEME, ultrasound-assisted emulsification-microextraction; VALLM, vortex-assisted liquid-liquid microextraction.

\section{References}

1. R. Cermak, S. Wolffram, Curr. Drug Metab. 2006, 7(7), 729744. DOI:10.2174/138920006778520570

2. L. Jiang, G. Fang, Y. Zhang, G. Cao, S. Wang, J. Agric. Food Chem. 2008, 56(24), 11571-11577. DOI:10.1021/jf802567r

3. S. Subash, P. Subramanian, Mol. Cell. Biochem. 2009, 327, 153. DOI:10.1007/s11010-009-0053-1

4. M. Lesjak, I. Beara, N. Simin, D. Pintać, T. Majkić, K. Bekvalac, D. Orčić, N. Mimica-Dukić, J. Funct. Food 2018, 40, 68-75. DOI:10.1016/j.jff.2017.10.047

5. F. Fang, J.-M. Li, Q.-H. Pan, W.-D. Huang, Food Chem. 2007, 101, 428-433. DOI:10.1016/j.foodchem.2005.12.036 
6. T. H. Sani, M. R. Hadjmohammadi, M. H. Fatemi, J. Sep. Sci. 2020, DOI: $10.1002 /$ jssc. 201900527

7. M. R. Hadjmohammadi, S. S. S. Nazari, J. Sep. Sci. 2013, 36, 3667-3672. DOI:10.1002/jssc.201300920

8. M. A. Maobe, L. Gitu, E. Gatebe, H. Rotich, P. O. Box, Acad. J. Cancer Res. 2012, 5(2), 31-39.

DOI:10.5829/idosi.ajcr.2012.5.2.66210

9. Y. Nolvachai, C. Kulsing, R. I. Boysen, M. T. Hearn, P. J. Marriott, J. Sep. Sci. 2014, 37, 1018-1025. DOI:10.1002/jssc.201301009

10. J. M. Herrero-Martínez, F. Z. Oumada, M. Rosés, E. Bosch, C. Ràfols, J. Sep. Sci. 2007, 30, 2493-2500.

DOI:10.1002/jssc.200700124

11. D. Goltz, S. Ahmadi, J. Crawford, D. Craig, J. Liq. Chromatogr. Relat. Technol. 2016, 39(16), 768-774.

DOI:10.1080/10826076.2016.1247714

12. M. L. Yola, V. K. Gupta, T. Eren, A. E. Şen, N. Atar, Electrochim. Acta 2014, 120, 204-211.

DOI:10.1016/j.electacta.2013.12.086

13. A. Michalkiewicz, M. Biesaga, K. Pyrzynska, J. Chromatogr. A 2008, 1187, 18-24. DOI:10.1016/j.chroma.2008.02.001

14. M. R. Hadjmohammadi, S. Nazari, K. Kamel, Chromatographia 2009, 69, 1291-1297. DOI:10.1365/s10337-009-1073-4

15. S. M. Majidi, M. R. Hadjmohammadi, J. Sep. Sci. 2019. DOI:10.1002/jssc. 201900234

16. S. Kongkiatpaiboon, P. Tungsukruthai, K. Sriyakool, K. Pansuksan, A. Tunsirikongkon, H. Pandith, J. chromatogr. Sci. 2017, 55, 346-350. DOI:10.1093/chromsci/bmw191

17. J. Xie, L. Zhu, H. Luo, L. Zhou, C. Li, X. Xu, J. Chromatogr. A 2001, 934, 1-11. DOI:10.1016/S0021-9673(01)01294-8

18. E. Ranjbari, P. Biparva, M. R. Hadjmohammadi, Talanta 2012, 89, 117-123. DOI:10.1016/j.talanta.2011.11.079

19. M. Rezaee, Y. Assadi, M.-R. M. Hosseini, E. Aghaee, F. Ahmadi, S. Berijani, J. Chromatogr. A 2006, 1116, 1-9

DOI:10.1016/j.chroma.2006.03.007

20. M. R. K. Zanjani, Y. Yamini, S. Shariati, J. Å. Jönsson, Anal. Chim. Acta 2007, 585, 286-293. DOI:10.1016/j.aca.2006.12.049

21. E. Yiantzi, E. Psillakis, K. Tyrovola, N. Kalogerakis, Talanta 2010, 80, 2057-2062. DOI:10.1016/j.talanta.2009.11.005
22. J. Regueiro, M. Llompart, C. Garcia-Jares, J. C. Garcia-Monteagudo, R. Cela, J. Chromatogr. A 2008, 1190, 27-38.

DOI:10.1016/j.chroma.2008.02.091

23. M. A. Farajzadeh, M. R. A. Mogaddam, Anal. Chim. acta 2012, 728, 31-38. DOI:10.1016/j.aca.2012.03.031

24. M. A. Farajzadeh, A. Mohebbi, A. Pazhohan, M. Nemati, M. R. A. Mogaddam, TrAC Trends in Anal. Chem. 2020, 122, 115734. DOI:10.1016/j.trac.2019.115734

25. M. Torbati, A. Mohebbi, M. A. Farajzadeh, M. R. A. Mogaddam, Anal. Chim. acta 2018, 1032, 48-55.

DOI:10.1016/j.aca.2018.06.025

26. A. Mohebbi, S. Yaripour, M. A. Farajzadeh, M. R. A. Mogaddam, J. Chromatogr. A 2018, 1571, 84-93. DOI:10.1016/j.chroma.2018.08.022

27. A. Fallah, M. R. Hadjmohammadi, J. Iran. Chem. Soc. 2020, 1-8. DOI:10.1007/s13738-020-01895-1

28. B. Alves Rocha, A. R. M. de Oliveira, F. Barbosa, Talanta 2018, 183, 94-101. DOI:10.1016/j.talanta.2018.02.052

29. D. Ge, Y. Zhang, Y. Dai, S. Yang, J. Sep. Sci. 2018, 41, 16351643. DOI: $10.1002 /$ jssc. 201701282

30. M. Shirani, S. Habibollahi, A. Akbari, Food chem. 2019, 281, 304-311. DOI:10.1016/j.foodchem.2018.12.110

31. X. You, Z. Xing, F. Liu, X. Zhang, Anal. Chim. acta, 2015, 875, 54-60. DOI:10.1016/j.aca.2015.03.033

32. R. L. Plackett, J. P. Burman, Biometrika 1946, 33, 305-325. DOI: $10.2307 / 2332195$

33. M. Hadjmohammadi, H. Karimiyan, V. Sharifi, Food chem. 2013, 141, 731-735. DOI:10.1016/j.foodchem.2013.02.083

34. P. Viñas, N. Martínez-Castillo, N. Campillo, M. Hernández-Córdoba, J. Chromatogr. A 2011, 1218, 639-646.

DOI:10.1016/j.chroma.2010.12.026

35. A. Asfaram, M. Ghaedi, H. Javadian, A. Goudarzi, Ultrason. Sonochem. 2018, 47, 1-9.

DOI:10.1016/j.ultsonch.2018.04.008

36. N. N. Nia, M. R. Hadjmohammadi, Anal. Methods 2019 , 11(40), 5134-5141. DOI:10.1039/C9AY01704F

37. K. Ishii, T. Furuta, Y. Kasuya, J. Chromatogr. B 2003, 794, 4956. DOI:10.1016/S1570-0232(03)00398-2

\section{Povzetek}

$\mathrm{V}$ tej študiji smo uporabili hitro in učinkovito metodo za ekstrakcijo in določitev morina in kvercetina v vzorcih sadnih sokov. Metoda je osnovana na mikroekstrakciji tekoče-tekoče s pomočjo zraka in strjevanja plavajoče kapljice topila, ter HPLC-UV. Učinek 7 pomembnih parametrov na izkoristek ekstrakcije smo preiskovali in optimizirali s Plackett-Burmanovim načrtom in centralnim kompozitnim načrtom. Glede na rezultate pri Plackett-Burmanovem načrtu ionska moč vzorca, aspiracijsko-disperzijski cikli, hitrost in čas centrifugiranja nimajo znatnega vpliva na ekstrakcijo morina in kvercetina. Optimizirani pogoji ekstrakcije so bili: volumen ekstrakcijskega topila 83,6 $\mu \mathrm{L}$, pH vzorca 4,34 ter 1-undekanol kot ekstrakcijsko topilo. Pod temi pogoji je bila kalibracijska krivulja linearna v območju $1-1000 \mathrm{ng} / \mathrm{mL}$ za morin in 0,5-1000 ng/mL za kvercetin, koeficienti determinacije pa so bili nad 0,99. Meja zaznave je bila 0,3 ng/mL za morin in $0,2 \mathrm{ng} / \mathrm{mL}$ za kvercetin. Izkoristek ekstrakcije za $10 \mathrm{ng} / \mathrm{mL}$ morina in kvercetina je bil 98,9 \% oziroma 96,5 \%, medtem ko je bil relativni standardni odklon $(n=3)$ nižji od 3,2 \%.

Except when otherwise noted, articles in this journal are published under the terms and conditions of the Creative Commons Attribution 4.0 International License 